\title{
Change of self-discharge mechanism as a fast tool for estimating long-term stability of ionic liquid based supercapacitors
}

\author{
Ann Laheäär ${ }^{1}$, Ana Arenillas ${ }^{2}$, François Béguin ${ }^{1 z}$ \\ ${ }^{1}$ Institute of Chemistry and Technical Electrochemistry, Poznan University of \\ Technology, Berdychowo 4, 60-965 Poznan, Poland \\ ${ }^{2}$ INCAR-CSIC, C/ Francisco Pintado Fe 26, 33011 Oviedo, Spain
}

\begin{abstract}
A systematic study is presented on self-discharge (SD) characteristics and leakage current levels of supercapacitors based on various carbon materials in ionic liquids: 1-ethyl-3-methylimidazolium bis(trifluoromethanesulfonyl)imide (EMImTFSI) and 1-butyl-3-methylimidazolium tetrafluoroborate $\left(\mathrm{BMImBF}_{4}\right)$. The higher SD rate occurring with partly mesoporous carbon xerogels, opposed to microporous activated carbon, suggests underlying faradaic induced processes rather than SD governed by charge redistribution. The passivation of some surface active sites of carbon xerogels by high-temperature di-hydrogen treatment resulted in reduced SD extent. The cell potential hold dependence of SD was studied for individual electrodes, showing changes of SD mechanism in EMImTFSI for both electrode polarities at cell potential higher than $2.8 \mathrm{~V}$, against $\sim 3.4 \mathrm{~V}$ and $>3.6 \mathrm{~V}$ for the negatively and positively charged electrodes in $\mathrm{BMImBF}_{4}$.
\end{abstract}

A good correlation was established between the electrochemical stability limits determined by long-lasting floating tests and the limits suggested by changes in the SD mechanism and increase in measured leakage current. Hence, SD and leakage current analysis is a sensitive and much faster tool for determining the maximum cell 
potential applicable to supercapacitors than life time tests by floating, and should be more extensively applied in the future for such objective.

${ }^{\mathrm{z}}$ E-mail: francois.beguin@ @ put.poznan.pl

\section{Introduction}

Electrical double-layer capacitors (EDLCs), also called supercapacitors (SCs), are attractive energy storage devices owing to characteristics such as high specific power in combination with good electrical efficiency, excellent long-term stability, reliability in operation, no need for maintenance, etc. [1]. However, in addition to specifying the optimum cell potential for long-term stability, SC's ability to retain the charged state should be evaluated. The latter is generally expressed by the spontaneous potential decay which occurs when a SC is set to open circuit conditions after charging, and is referred to as self-discharge (SD). Evaluating the extent of SD in time is important both on the point of view of available energy and power (both dependent on square of cell potential) when a SC is used some time after charging, and for understanding the electrolyte species/carbon host interactions in the charged system. SD can be caused by several different processes, such as charge redistribution, ohmic leakage (due to faulty device construction) or faradaic reactions with either activation- or diffusioncontrolled mechanism [2-6]. Examining the SD profiles of individual electrodes enables to detect the potential limits, where faradaic reactions start to take place as well as the type of degradation process. For example, a linear relation between potential and logarithm of SD time refers to an activation-controlled process related to high concentration of reacting species in the electrolyte or being attached to or part of an electrode, as well as decomposition reactions caused by overcharge. A linear potential decline in square-root of time expresses a diffusion-controlled SD process 
related to reacting species in low concentration, such as impurities in the electrolyte $[2,3,7,8]$.

According to simulations, the carbon pore size and shape (diameter, length, presence of bottlenecks, etc.) have a significant influence on charge redistribution induced SD $[9,10]$. Indeed, due to the diffusion resistance of the electrolyte confined in the carbon porosity, pores of different geometries are charged at different rates, i.e., less accessible pores might not be uniformly charged during the generally short duration of SC charging. Therefore, at open circuit conditions after charging, redistribution of adsorbed ions takes place from higher to lower surface charge density areas in the porosity. Simulations using the de Levi transmission line model show that the initial potential decline due to charge redistribution is more pronounced with carbons of wider average pore size. However, the overall cell potential decay, after charge equalization over the pore walls, is more extensive in case of smaller average pore size. This effect is explained by the slower charging of the bottom of a narrow pore due to the electrolyte resistance inside the pore, leading to a more extensive potential loss measured at the pore entrance after some period at open circuit [9]. It has been shown that it takes very long time to fully charge high surface area carbons, i.e. carbons with high volume of narrow pores (estimated to be in tens of hours [4]), thus the effect of charge redistribution is practically unavoidable. Therefore, it is difficult to precisely determine the self-discharge mechanism, as the potential decline profile is influenced by the rearrangement of electrode surface charge. For example, whereas linear potential vs. $\log t$ dependence is characteristic of activation-controlled SD, the slope of such SD curve may be influenced by a parallel charge redistribution process and still remain linear [4]. In practical situation, the separation of processes contributing to the potential decay is much more complicated 
than in model pores due to the distribution in pore sizes and unknown pore geometries (presence of bottlenecks, etc).

A recent perspective article [8] addresses the different possible SD processes in various supercapacitor designs, with literature overview being limited to only aqueous and organic electrolyte based systems. To date, there are very few and non-systematic studies on SD in ionic liquid (IL) based SCs. Leakage current and self-discharge of pyrrolidinium ILs-based asymmetric SCs have been studied only on the device level by Soavi et al [11]. They concluded that, despite feasible high cell potential up to 3.5 $\mathrm{V}$ during galvanostatic cycling, the latter should be limited to $3.2 \mathrm{~V}$ in order to reduce the leakage current and SD rate. They also observed lower leakage current and extent of SD for IL-based SCs in comparison with conventional propylene carbonate (PC) based electrolyte. Handa et al showed somewhat inferior SD of device in PCelectrolyte compared to imidazolium ILs [12], however at a fairly low cell potential of $2.0 \mathrm{~V}$.

The attractiveness of ILs lies mainly in the possibility for higher cell potentials, in comparison with organic solvent-based electrolytes, as well as non-volatility and thermal stability [1]. However, ILs' rather high viscosity and low ionic conductivity are a disadvantage from the device power point of view. The electrochemical stability of IL electrolytes is generally evaluated by cyclic voltammetry (CV) on either planar electrodes or high surface area carbons. However, the criteria for determining precise potential limits are rather arbitrary, leading to vagueness in the reported values. Weingarth et al proposed to modify the method of electrolyte stability determination from $\mathrm{CV}$ [13], which was previously presented by $\mathrm{Xu}$ et al for non-aqueous electrolyte/carbon interface $[14,15]$. Such method relies on the evaluation of the total charge quantity ratio for the charge and discharge processes, and change of the ratio 
with gradual step-by-step increase of absolute vertex potentials values on a carbon working electrode (for both positive and negative potential directions). The modification in Ref. [13] enables a more accurate determination of the potentials related with the appearance of Faradaic currents due to electrolyte decomposition. For selected ionic liquid based systems, Weingarth et al confirmed the potential limits estimated by floating on the basis of $20 \%$ capacitance fading as cell failure criterion. In industry, the life time of SCs is defined by the time duration from the first use in application until one of the following end-of-life criteria is reached - either $20 \%$ decrease in capacitance $(C)$ or $100 \%$ increase in resistance $[1,16,17]$ therefore both criteria are monitored in the current paper for more accurate conclusions.

This paper includes a systematic study of SD and leakage current characteristics at various cell potentials combined with parallel tests of accelerated ageing (capacitance and resistance dependence on floating time) for different imidazoliumbased IL/porous carbon SCs. The leakage current and SD are described on a device level, and SD mechanistic studies are presented for individual electrodes through measurements in two-electrode cells equipped with a reference electrode. It was found that the carbon porous texture and post-synthesis surface passivation, as well as ionic liquid properties, have a pronounced effect on SD. Diffusion-controlled SD occurs in mainly microporous carbons below the stability limits of ILs, whereas an activationcontrolled mechanism was established for mesoporous carbons. Generally, the SD is determined by faradaic reactions involving impurities in the IL or in carbon (as well as corrosion processes and created impurities in IL) rather than charge redistribution. The potential limits suggested by increase in leakage current values and by changes in electrodes' SD process are in good correlation with the limits determined by potentiostatic floating. 


\section{Experimental}

\subsection{Physico-chemical characterization of carbons}

Three carbons having considerably different specific surface area, porosity and surface functionality were selected for a detailed study of the SD behavior in ILs. The commercially available YP-80F (Kuraray) is a microporous activated carbon with particle size in the range of 1-20 micrometers. Two carbon xerogels, a high specific surface area CXER-H with narrow mesopores and a low specific surface area mainly mesoporous CXER-L, were synthesized by controlled polycondensation of resorcinolformaldehyde [18] and subsequent carbonization-activation with $\mathrm{CO}_{2}$ at $1000{ }^{\circ} \mathrm{C}$ for various times [19]. The activated CXER samples were milled so as to have particle sizes below 75 micrometers. The choice of both types of carbons in combination with IL electrolytes was determined according to knowledge from the literature. On the one hand, the studies on carbons with narrow pore size distribution suggest that for maximum double-layer capacitance, the average pore size should be very close to the ion size so that only one ion fits with the pore width [20]. On the other hand, mesoporous carbons were developed for IL-based EDLCs to take the advantage of forming the double-layer on both pore walls (optimum pore size $2-3 \mathrm{~nm}$ ), and avoid electrolyte starving effects and slow ion rearrangement observed with high specific surface area microporous carbons of pore diameter below $1 \mathrm{~nm}[21,22]$. The porous texture of the carbon samples, presented in Table 1, was determined by $\mathrm{N}_{2}$ adsorption/desorption at $-196{ }^{\circ} \mathrm{C}$ (ASAP2020, Micromeritics). Prior to the analysis, the samples were degassed under vacuum for $12 \mathrm{~h}$ at $350{ }^{\circ} \mathrm{C}$. The specific surface area was estimated by the Brunauer-Emmett-Teller (BET) theory, and the micro- and mesopore volumes were obtained from the cumulative pore size distribution (PSD) determined by the non-local density functional theory (2D-NLDFT) applying a slit- 
shape pore model $[23,24]$. The average micro- and mesopore sizes were determined from the integration of PSD area for pores below $2 \mathrm{~nm}$ and in the range 2-50 nm, respectively.

Table 1. Porous texture characteristics of carbons from $\mathrm{N}_{2}$ adsorption/desorption isotherms at $-196^{\circ} \mathrm{C}$.

\begin{tabular}{|c|c|c|c|c|c|}
\hline \multirow{2}{*}{ Carbon } & \multirow{2}{*}{$\begin{array}{l}S_{\mathrm{BET}} / \\
\mathrm{m}^{2} \mathrm{~g}^{-1}\end{array}$} & \multirow{2}{*}{$\begin{array}{l}V_{\text {micro }} / \\
\mathrm{cm}^{3} \mathrm{~g}^{-1}\end{array}$} & \multirow{2}{*}{$\begin{array}{c}V_{\text {meso }} / \\
\mathrm{cm}^{3} \mathrm{~g}^{-1}\end{array}$} & \multicolumn{2}{|c|}{ Average pore size } \\
\hline & & & & $<2 \mathrm{~nm}$ & $2-50 \mathrm{~nm}$ \\
\hline YP-80F & 2307 & 0.80 & 0.23 & 1.01 & 2.78 \\
\hline CXER-H & 2751 & 0.89 & 0.64 & 1.07 & 3.27 \\
\hline CXER-H:H2 & 2703 & 0.85 & 0.64 & 1.10 & 3.20 \\
\hline CXER-L & 903 & 0.30 & 0.84 & 0.67 & 16.55 \\
\hline
\end{tabular}

$S_{\mathrm{BET}}-\mathrm{BET}$ specific surface area, $V_{\text {micro }}$ - micropore and $V_{\text {meso }}-$ mesopore volumes determined by the 2D-NLDFT method.

High surface area carbons have many free radicals, which can either be delocalized in the $\mathrm{sp}^{2}$ network or behave as active sites on the carbon surface [25]. These active sites presumably play an important role in the extent of electrolyte decomposition at high cell potentials and in the supercapacitor self-discharge behavior. Unfortunately, there is no well-established method for radical species characterization and quantification. In order to deactivate the surface, the carbons were reductively post-treated under a flow of $\mathrm{H}_{2}$ and $\mathrm{N}_{2}$ mixture (1:4 volume ratio, $250 \mathrm{~mL} \mathrm{~min}{ }^{-1}$ ) at $700{ }^{\circ} \mathrm{C}$ for $2 \mathrm{~h}$ in an airtight quartz tube. During heating up at $15^{\circ} \mathrm{C}$ $\min ^{-1}$ and cooling down to room temperature, a $250 \mathrm{~mL} \mathrm{~min}^{-1}$ flow of pure $\mathrm{N}_{2}$ was applied. The hydrogen-treated carbons are hereafter noted as "carbon name:H2". The example of CXER-H:H2 in Table 1 indicates that the porous texture of the carbon powders is not altered by such post-treatment, which also applies for the other hydrogen-treated carbons (YP-80F:H2 and CXER-L:H2).

The amount of oxygenated surface functional group of carbons was determined by temperature-programmed desorption (TPD), coupling a TG equipment (TG209 F1 
Iris, NETZSCH) with a mass spectrometer (QMS 403C Aëolos, NETZSCH). The evolution of $\mathrm{H}_{2} \mathrm{O}, \mathrm{CO}$ and $\mathrm{CO}_{2}$ was monitored during heating the samples under helium gas flow. The three pristine carbons under study contain $1.4-1.9 \mathrm{wt} \%$ of surface-bound oxygen. Elemental analysis enabled to determine the total amount of oxygen, including in-built oxygen, which is not detected by TPD. The oxygen amount was slightly higher than obtained by TPD, i.e. $2.8 \mathrm{wt} \%$ in CXER-L, $3.4 \mathrm{wt} \%$ in CXER-H, and $2.1 \%$ YP-80F.

Inductively coupled plasma optical emission spectroscopy (ICP-OES; VistaMPX, Varian Inc.) was used to determine traces of metal impurities present in the samples. The detection limits of the method are: $\mathrm{Cd}, \mathrm{Cr}, \mathrm{Mn}, \mathrm{Ti}, \mathrm{V}<0.1 \mathrm{ppm}$; Co, $\mathrm{Cu}, \mathrm{Fe}, \mathrm{Mg}, \mathrm{Ni}, \mathrm{Pb}, \mathrm{Zn}<0.5$ ppm; Ag, Al, K, Na < 1.0 ppm; Ca $<5.0$ ppm; As, $\mathrm{P}, \mathrm{Se}$, $\mathrm{Sn}<10.0 \mathrm{ppm}$.

\subsection{Ionic liquid electrolytes}

The ionic liquids used in the study were 1-ethyl-3-methylimidazolium bis(trifluoromethanesulfonyl)imide (EMImTFSI; Solvionic, 99.9\%, $\mathrm{Cl}^{-}, \mathrm{Br}^{-}<1 \mathrm{ppm}$, $\left.9 \mathrm{mS} \mathrm{cm}{ }^{-1}, 35 \mathrm{cP}\right)$ and 1-butyl-3-methylimidazolium tetrafluoroborate $\left(\mathrm{BMImBF}_{4}\right.$; Iolitec, $\left.99 \%, \mathrm{Cl}^{-}, \mathrm{Br}^{-}<100 \mathrm{ppm}, 3.5 \mathrm{mS} \mathrm{cm}{ }^{-1}, \sim 180 \mathrm{cP}\right)$. As the water content by Karl Fisher titration (831 KF Coulometer, Metrohm) in the purchased $\mathrm{BMImBF}_{4}$ was 320 ppm, this IL was additionally dried at $\sim 100^{\circ} \mathrm{C}$ under vacuum for $12 \mathrm{~h}$, with liquid nitrogen cooling to trap evaporated $\mathrm{H}_{2} \mathrm{O}$. After drying, the water content was $22 \mathrm{ppm}$ in $\mathrm{BMImBF}_{4}$, reaching a comparable level with EMImTFSI containing $17 \mathrm{ppm}$ of water traces. ICP-OES (Vista-MPX, Varian Inc.) analysis on the ILs showed that they did not contain metallic impurities with concentration higher than the detection limits of the method. The sizes of IL ions are presented in Figure S1 (see Supplementary materials). 


\subsection{Electrochemical measurements}

Electrodes were prepared from dough comprising $80 \mathrm{wt} \%$ porous carbon powder, $10 \mathrm{wt} \%$ carbon black additive (Super C65, Imerys) and $10 \mathrm{wt} \%$ PTFE (60 wt\% dispersion in water, DuPont). These components were mixed by stirring in ethanol at $60^{\circ} \mathrm{C}$ until alcohol evaporation and homogeneous dough was obtained. Then, the dough was press-rolled to $\sim 120 \mu \mathrm{m}$ thick sheets, from which $0.785 \mathrm{~cm}^{2}(6-7 \mathrm{mg})$ and $0.50 \mathrm{~cm}^{2}(3.8-4.5 \mathrm{mg})$ round electrodes were cut for electrochemical testing in coin cells and Swagelok-type test cells, respectively; the electrodes were dried for $12 \mathrm{~h}$ under vacuum at $120{ }^{\circ} \mathrm{C}$. A glass microfiber porous membrane $(\sim 260 \mu \mathrm{m}, \mathrm{GF} / \mathrm{A}$, Whatman ${ }^{\mathrm{TM}}$ ) was applied as separator. Before assembly of the cells under argon atmosphere in a glove-box $\left(\mathrm{O}_{2}\right.$ and $\mathrm{H}_{2} \mathrm{O}<1 \mathrm{ppm}$, Jacomex $)$, the carbon electrodes were immersed in IL and outgassed under vacuum for $2 \mathrm{~h}$ in order to release gas trapped in the pores and enhance soaking with somewhat viscous IL.

Stainless steel 304 coin cells (CR2025, MTI Corp.) were assembled for electrochemical evaluation of capacitors with various carbon/IL couples. For simultaneous monitoring of cell potential $(U)$ and individual electrode potentials $\left(E_{\text {pos }}\right.$ and $E_{\text {neg }}$ ) during SD, two-electrode Swagelok-type teflon cells, with 316L stainless steel current collectors, were equipped with a $\mathrm{Ag} / \mathrm{Ag}^{+}$pseudo-reference electrode (RE).

The electrochemical measurements were performed with a VMP3 multichannel potentiostat/galvanostat (Biologic). $\mathrm{CV}$ potential scan rates between 1 and $50 \mathrm{mV} \mathrm{s}^{-1}$ and GC current density of $0.1 \mathrm{~A} \mathrm{~g}^{-1}$ were applied. The leakage current was measured during a $2 \mathrm{~h}$ hold at a fixed cell potential $(U)$, and thereafter the cell (and electrode) SD profiles were recorded at open circuit during 24 hours. However, as the leakage current reached stable values already after 2000s, the plots in Figure 3 were limited to 
4000s. During the potentiostatic floating tests, the leakage current was recorded during $2 \mathrm{~h}$ potential hold periods at $U$, after which the series resistance $(E S R)$ and discharge capacitance were evaluated by recording five galvanostatic cycles. Such sequence was repeated until reaching a total floating time of 600 hours. Due to slight non-linearity of the galvanostatic characteristics, the capacitance $(C)$ was calculated by integration of the discharge curve as described in [26] and Equations (1) and (2).

$$
\begin{aligned}
& E_{\mathrm{int} / \mathrm{D}}=\int_{U_{\max }}^{U_{\min }} I d U=I \int_{t\left(U_{\max }\right)}^{t\left(U_{\min }\right)} U(t) d t, \\
& C_{\mathrm{int} / \mathrm{D}}=\frac{2 E_{\mathrm{in} t / D}}{U_{\text {max }}^{2}} .
\end{aligned}
$$

A Scanning Electron Microscope (SEM, Hitachi Model S-3400 N) equipped with an Energy Dispersive X-Ray Spectrometer (EDX) was used to analyze the surface of coin cell current collectors as well as to determine metal traces on electrode surfaces after potentiostatic floating.

\section{Results and discussion}

3.1. Self-discharge and leakage current of 2-electrode coin cells in relation to carbon properties and ionic liquid composition

The cyclic voltammograms of coin cells based on YP-80F electrodes showed slightly better charge propagation in EMImTFSI than in $\mathrm{BMImBF}_{4}$ (see Supplementary materials, Figure S2). The $24 \mathrm{~h}$ self-discharge profiles of 2-electrode coin cells, after a $2 \mathrm{~h}$ potentiostatic hold at $U=2.5 \mathrm{~V}$, are presented in Figure 1 for the various carbon based electrodes in as-received EMImTFSI and $\mathrm{BMImBF}_{4}$. The cell potential hold of $2.5 \mathrm{~V}$ has been chosen as a kind of "safe limit", where the studied systems should be rather electrochemically stable, and the SD processes observable 
without extensive effects from possible degradation. The fastest decline in $U$ takes place during the first few hours at open circuit, after which the rate decreases. The extent of initial drop in $U$ follows the sequence YP-80F $<$ CXER-H $<$ CXER-L in both ILs, which could be related to the increasing $V_{\text {meso }} / V_{\text {micro }}$ ratio (Table 1 ) and average mesopore size. According to simulations [9], if charge redistribution would be the determining mechanism of potential decay during prolonged open circuit conditions, the $24 \mathrm{~h} \mathrm{SD}$ end-potential should be lower with the microporous YP-80F carbon. Namely, after charging, higher ion population gradients exist between the bottom and mouth of small pores compared to wider pores, leading to more extensive surface charge equalization, and the potential measured at the pore mouth should decrease quicker. However, as the final $U$ is higher for carbons with high $V_{\text {micro }}$ (Figure 1), the main cause of SD in the given systems is rather of faradaic origin.

Since the surface oxygen content determined by TPD is nearly the same for the three carbons, i.e. 1.4, 1.4 and 1.9 wt\% in YP-80F, CXER-H and CXER-L, respectively, the contribution to $\mathrm{SD}$ of Faradaic reactions involving oxygenated surface functionalities is expected to be comparable. In case of the commercial YP$80 \mathrm{~F}$ carbon, which is expected to have been post-treated to passivate the surface as part of production process, the di-hydrogen treatment at $700{ }^{\circ} \mathrm{C}$ did not change the SD behavior (YP-80F and YP-80F:H2 in Figure 1a). On the contrary, after treatment of the carbon xerogels CXER-H and CXER-L under di-hydrogen at $700{ }^{\circ} \mathrm{C}$, the SD rate in EMImTFSI for the respective capacitors based on CXER-H:H2 and CXER-L:H2 is noticeably reduced, as shown in Figure 1a by the slower $U$ decline. The charge redistribution contribution to SD should not be altered by the di-hydrogen treatment as the porosity characteristics in Table I remain the same for CXER-H:H2 and CXERH. Additionally, since the amount of oxygen detected by TPD is 1.4 and $1.2 \mathrm{wt} \%$ for 
CXER-H and CXER-H:H2, respectively, the change in SD rate is also not related to a modification of oxygenated surface functionality. Figure 1a shows that CXER-H:H2 has very similar SD profile to the YP-80F and YP-80F:H2 electrodes, with all three samples having comparable micropore volume and average micropore size (Table 1), except that CXER-H:H2 has quite high volume of mesopores and therefore SD must still be partly of faradaic origin. One possible explanation for the reduced SD of the two carbon xerogels after hydrogen treatment could be the passivation of paramagnetic sites (active sites) created on the carbon surface during the synthesis [25].

In $\mathrm{BMImBF}_{4}$, the two high surface area carbons (YP-80F and CXER-H) have slightly higher rate of SD throughout the $24 \mathrm{~h}$ period than in EMImTFSI (Figure 1b), which can be related to the more pronounced charge redistribution effect in the negatively charged electrodes after the $2 \mathrm{~h}$ potential hold period. Indeed, the more bulky $\mathrm{BMIm}^{+}(0.65 \mathrm{~nm} \times 0.99 \mathrm{~nm})$ cation is probably not as uniformly and quickly distributed in the narrow pores (average micropore size of $\sim 1.15 \mathrm{~nm}$ in both carbons) as is $\mathrm{EMIm}^{+}(0.62 \mathrm{~nm} \times 0.81 \mathrm{~nm})$ (see Figure S1 in Supplementary materials). This assumption is supported later in this publication by the more extensive potential change of the negatively charged electrode during the $24 \mathrm{~h}$ self-discharge period in $\mathrm{BMImBF}_{4}$ (see Figures $5 \mathrm{a}$ and $5 \mathrm{~b}$ ), as opposed to practically equal negative and positive electrodes' potential changes in EMImTFSI (see Figures $4 \mathrm{a}$ and $4 \mathrm{~b}$ ). The capacitor based on the CXER-L carbon has somewhat smaller SD extent in $\mathrm{BMImBF}_{4}$ than in EMImTFSI (Figures 1a and 1b), explained by the better accessibility of the $\mathrm{BMIm}^{+}$larger ion in the wider mesopores present in this carbon.

According to the self-discharge process analysis with respect to porous texture and carbon surface post-treatment, it is obvious that charge redistribution plays a role in 
the SD extent (difference between $\mathrm{BMImBF}_{4}$ and EMImTFSI). However, as carbons with large volume of mesopores show extensive SD, some additional Faradaic processes definitely take place, and their origin needs to be further analyzed.

Since it has been shown previously by Andreas et al [27] that increasing concentration of Fe impurities in aqueous $\mathrm{H}_{2} \mathrm{SO}_{4}$ electrolyte leads to more extensive SD in carbon based EDLCs due to shuttle reduction/oxidation reactions between the electrodes, we have also considered possible effects induced by metallic impurities in the ionic liquid based systems. $\mathrm{Fe}, \mathrm{Al}, \mathrm{Cu}$ and $\mathrm{Ca}$ were detected by ICP-EOS analysis in YP-80F at low concentrations of 17, 18, 28 and 40 ppm, respectively. By contrast, CXER-H and CXER-L contained much higher amounts of Fe (8000 ppm and 14000 ppm), $\mathrm{Cr}$ (1000 and 2000 ppm) and $\mathrm{Na}$ (4500 and 940 ppm). Thus, although the ILs themselves do not contain metallic impurities (paragraph 2.2), it can be suggested that Fe and other metal impurities inside the xerogel carbon electrodes could be source of faradaic SD processes also in ILs.

To summarize the 2-electrode cell measurements after cell potential hold $U=2.5$ $\mathrm{V}$, it can be claimed that the contribution of faradaic processes to self-discharge can be reduced by electrode surface "deactivation" under di-hydrogen, leading to somewhat slowed down redox electrolyte decomposition. Such treatment, however, obviously does not remove metallic impurities from the bulk of carbon powder. 

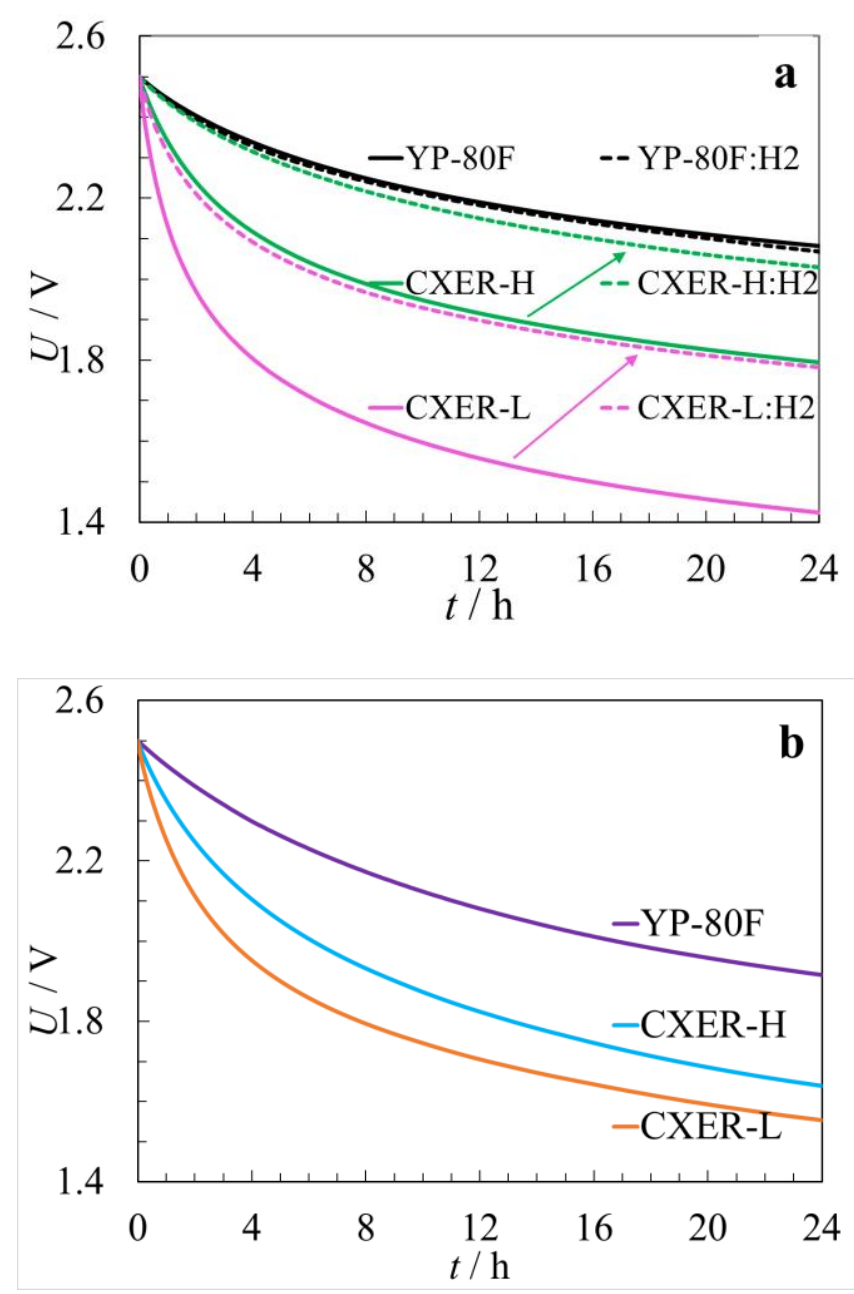

Figure 1. Self-discharge profiles $(U v s t)$ after $2 \mathrm{~h}$ potential hold at $U=2.5 \mathrm{~V}$ for EDLCs based on various electrode materials in (a) EMImTFSI and (b) $\mathrm{BMImBF}_{4}$ (320 ppm $\mathrm{H}_{2} \mathrm{O}$ ).

In order to better understand the processes behind the self-discharge of IL based EDL capacitors, the potential decay as well as leakage current profiles was also analyzed after cell potential hold higher than $2.5 \mathrm{~V}$. With CXER-H electrodes in EMImTFSI, the SD extent increased remarkably after cell potential hold $U$ equal to and higher than $2.8 \mathrm{~V}$, and the SD profiles were not well reproducible, indicating that $U=2.8 \mathrm{~V}$ is already close to the "safe limit" for this electrolyte, whilst in $\mathrm{BMImBF}_{4}$ the reproducibility was good up to $3.2 \mathrm{~V}$, and the SD extent started increasing slowly 
at cell potential hold higher than $3.2 \mathrm{~V}$ (Figure 2). The sudden change in SD extent above a certain cell potential hold reveals the starting of some extensive SD-inducing reactions, in addition to inevitable potential losses due to charge redistribution effects, and the problems linked with SD reproducibility indicate the occurrence of some nonsteady-state reactions, such as electrolyte decomposition on the electrodes' surface or electrolyte-induced corrosion of current collector(s). From the data in Figures 2a and $2 \mathrm{~b}$, it is also obvious that the SD after higher cell potential hold is initiated by completely different processes in the two electrolytes, as there is no sudden very extensive degradation in $\mathrm{BMImBF}_{4}$.
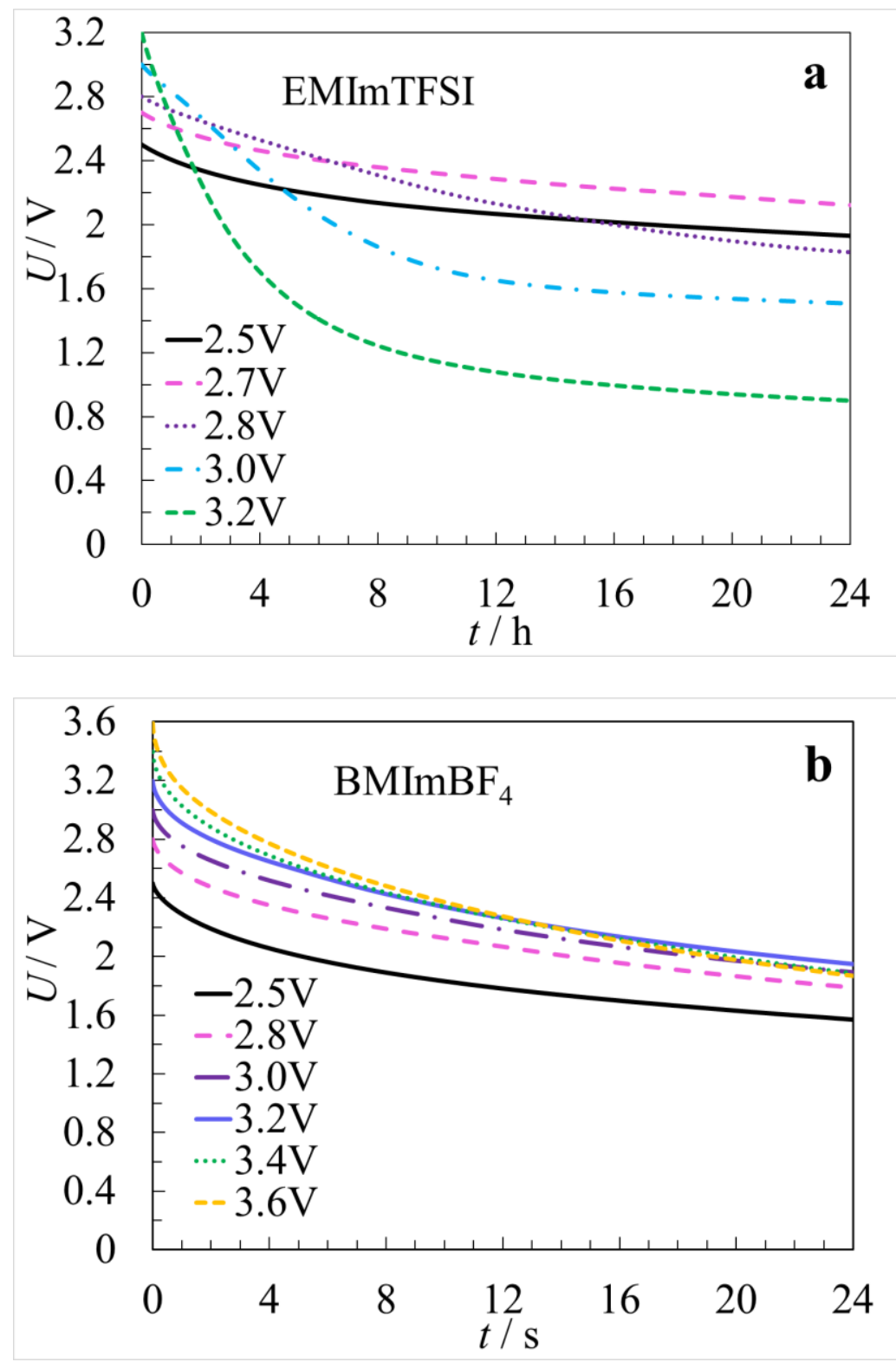
Figure 2. Self-discharge profiles ( $U v s t$ ) after $2 \mathrm{~h}$ hold at various cell potentials for EDLCs based on CXER-H electrode in (a) EMImTFSI and (b) $\mathrm{BMImBF}_{4}(320 \mathrm{ppm}$ ). The self-discharge noticeably increases at $U \geq 2.8 \mathrm{~V}$ in EMImTFSI, while it slowly increases at $U \geq 3.4 \mathrm{~V}$ for the EDLC based on $\mathrm{BMImBF}_{4}$.

The leakage current $\left(I_{\text {leak }}\right)$ of CXER-H/CXER-H capacitors in EMImTFSI and $\mathrm{BMImBF}_{4}\left(\mathrm{BMImBF}_{4}\right.$ was used as received with $320 \mathrm{ppm}$ of water in order to enable a direct comparison with the 2-electrode SD tests) was recorded during $2 \mathrm{~h}$ potential hold periods at various $U$ values (of which only 4000 second duration is displayed in Figure 3 for a better visualization of the initial processes). After a quick initial drop during the first few hundred seconds, a steady value of $I_{\text {leak }}$ is reached (Figure 3). The increase in the $I_{\text {leak }}$ steady value above a certain applied $U$ indicates the starting of faradaic process(es) requiring a higher applied current in order to keep a constant cell potential. The data on the EMImTFSI-based system in Figure 3a suggest that some degradation process(es) start to take place between $2.8 \mathrm{~V}$ and $3.0 \mathrm{~V}$, being in accordance with the reproducibility problems previously mentioned with SD measurements above $2.8 \mathrm{~V}$. In $\mathrm{BMImBF}_{4}$, the change in $I_{\text {leak }}$ level starts between 3.2 $\mathrm{V}$ and 3.4 V (Figure 3b), revealing higher electrochemical stability in this electrolyte. The trend in $I_{\text {leak }}$ change in the two ILs was practically independent of the carbon material used for electrodes. The somewhat higher $I_{\text {leak }}$ steady value in the $\mathrm{BMImBF}_{4}{ }^{-}$ based cells could be related to the higher water content of $320 \mathrm{ppm}$ compared to 17 ppm in EMImTFSI, as water is oxidized and reduced on the positive and negative electrodes, respectively, at such high applied cell potentials. Such observations on self-discharge and leakage current trend in EDLC single cells based on the two ionic liquids led to the interest in studying the SD mechanisms of individual electrodes as 
well as the relation between the stability potential limit determined by long-term floating and the change of SD characteristics. For this purpose, 2-electrode Swageloktype cells equipped with a reference electrode (RE) were used.
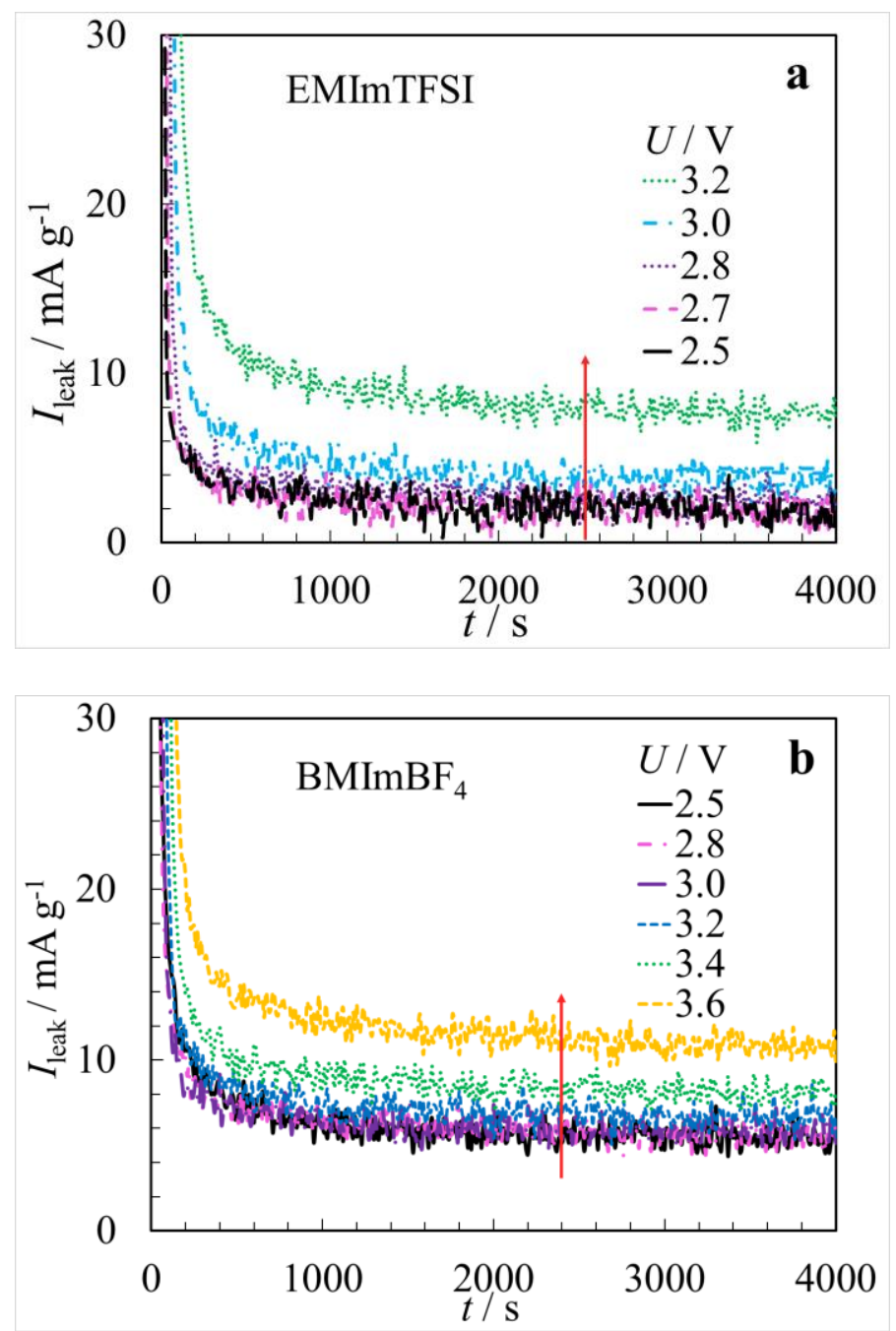

Figure 3. Leakage current profiles during 4000 second floating periods at various cell potentials for CXER-H/CXER-H cells in (a) EMImTFSI and (b) $\mathrm{BMImBF}_{4}(320 \mathrm{ppm}$ of water).

\subsection{Self-discharge mechanisms and limit potentials of individual electrodes}

By studying the self-discharge mechanisms of the positively and negatively charged electrodes separately, it is possible to better describe the influence of carbon and electrolyte properties on the cell SD behavior as well as to determine the stability 
potential limits, i.e. potential limits where extensive degradation processes are initiated. The changes in individual electrodes' potential after $2 \mathrm{~h}$ hold at various cell potential values are shown in Figure 4 for cells based either on CXER-H or CXER-L in EMImTFSI. In case of the high surface area carbon CXER-H (and also for YP$80 \mathrm{~F})$, the electrodes' potential $\left(E_{\mathrm{neg}}\right.$ and $\left.E_{\mathrm{pos}}\right)$ decay is linear vs. $t^{1 / 2}$ after hold at cell potential lower than $2.8 \mathrm{~V}$, i.e. the self-discharge is diffusion-controlled (Figures $4 \mathrm{a}$ and $4 \mathrm{~b}$ ). As moisture cannot be completely eliminated from ILs (17 ppm of $\mathrm{H}_{2} \mathrm{O}$ in EMImTFSI), as well as halides and dissolved oxygen may be present in small concentration, the diffusion-controlled SD can be related to the reactions of such impurities. It can also be noted that the absolute change in potential is roughly equal for the negative and positive electrodes in EMImTFSI (even at $U \geq 2.8 \mathrm{~V}$ where the SD is no longer diffusion controlled), showing that the charge redistribution effect is comparable for both signs of polarization, which fits well with the practically equal size of $\mathrm{EMIm}^{+}$and $\mathrm{TFSI}^{-}$ions (see Figure S1 in Supplementary materials). For the low surface area CXER-L carbon, the variation of $E_{\text {pos }}$ vs. $t^{1 / 2}$ is not linear even at $U<$ $2.8 \mathrm{~V}$ (Figure $4 \mathrm{~d}$, and also for $E_{\text {neg }}$ not shown on the Figure), and the initial plateau followed by linear decline of potential vs. $\log t$ characterizes an activation-controlled SD (Figure 4e). Also, the extent of potential change during SD is higher for CXER-L electrodes in EMImTFSI in comparison with CXER-H and YP-80F, yet similarly to the high surface area carbons, the absolute potential change is practically equal for both electrodes. The difference of SD extent between the two carbon xerogels is attributed to the wider mesopores in CXER-L which enable a better accessibility of the electrolyte to the $\mathrm{Fe}$ and $\mathrm{Cr}$ impurities.

At $U>2.8 \mathrm{~V}$, the SD mechanism in cells based on CXER-H (or YP-80F) electrodes turns to activation-controlled one (linear plot vs. $\log t$ ), accompanied by 
quick potential decay on both electrodes, thus indicating a change in the faradaic process(es) responsible for the SD (Figure 4c, not presented for positive electrode). Also in the CXER-L-based cells, the SD behavior seems to change at $U>2.8 \mathrm{~V}$, as the slope of the linear part in the $E_{\mathrm{pos}}$ (and also $E_{\text {neg }}$ ) vs. $\log t$ plot increases significantly, followed by slowed down SD in the end of the curve (Figure 4e), indicating that the SD process takes place in two potential-dependent steps. The exact process behind performance changes at cell potential hold $U>2.8 \mathrm{~V}$ is yet unknown, however the observation of two distinguished steps in the curves suggests reaching electrode potentials, where some faradaic process(es) caused by overcharge are initiated. The main process(es) behind the changes of SD mechanism on the negatively charged electrode after cell potential hold at $U>2.8 \mathrm{~V}$ are suggested to be related with the reduction of the $\mathrm{TFSI}^{-}$anion on the electrode surface by a series of radical reactions demonstrated in literature $[28,29]$. Floating tests on 2-electrode cells and post-mortem analysis of electrodes presented in Section 3.3 will enable to better interpret the SD mechanistic changes in EMImTFSI after cell potential hold $U>2.8$ V.

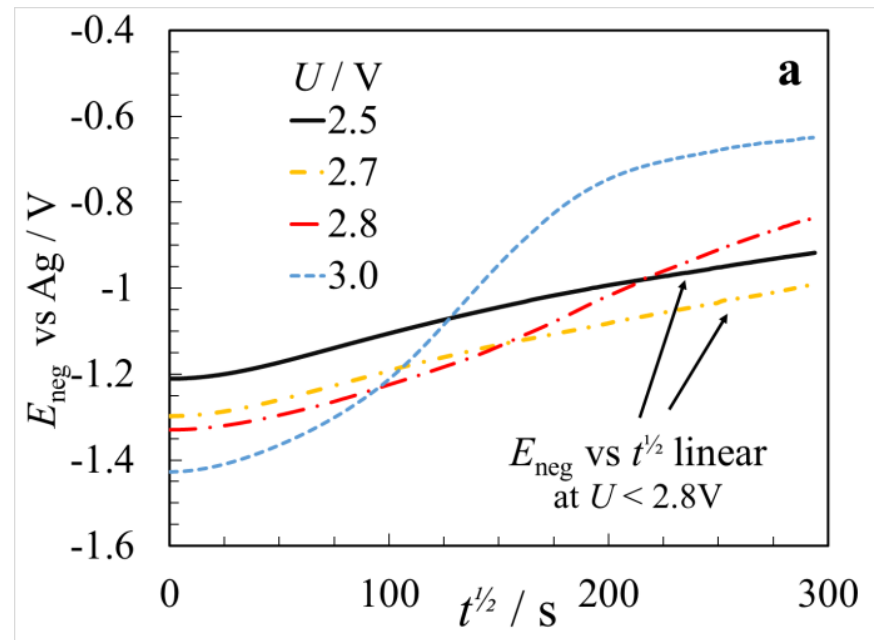



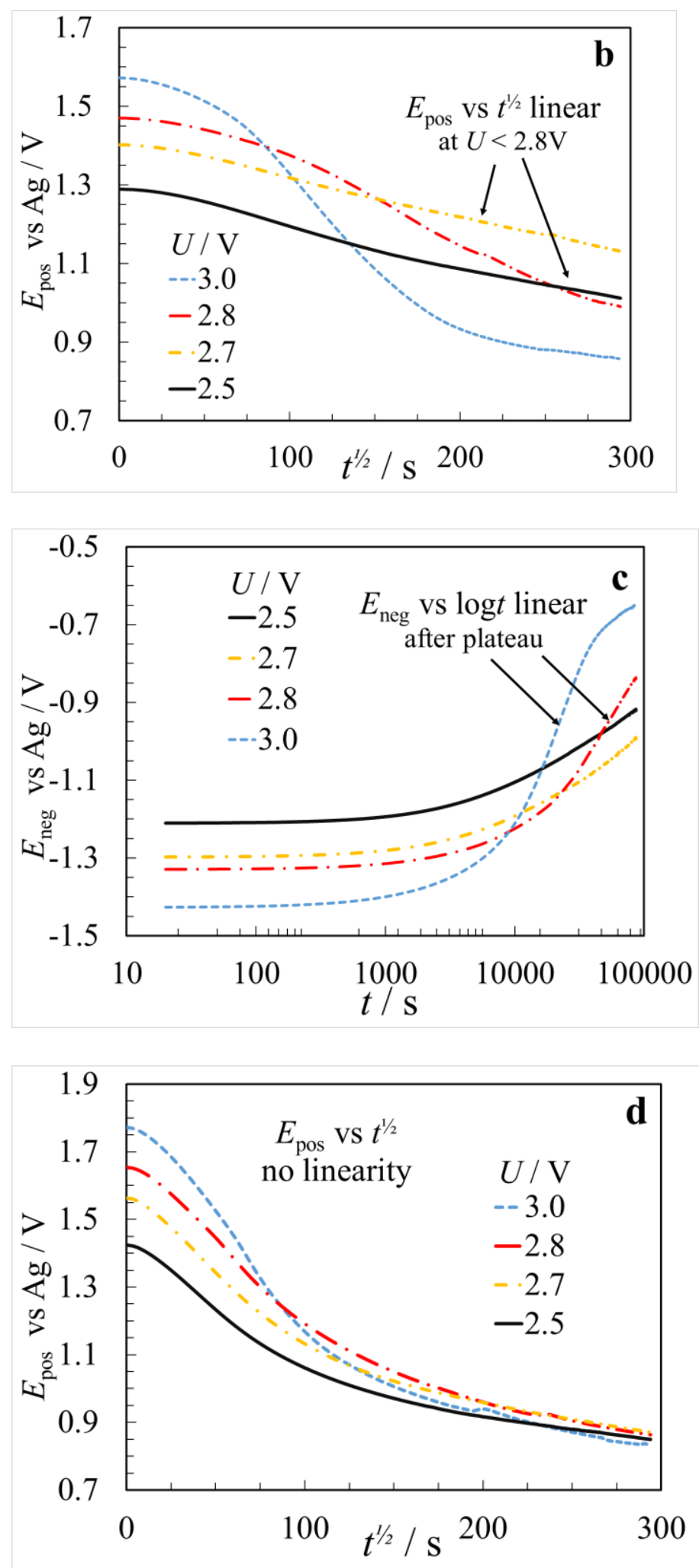


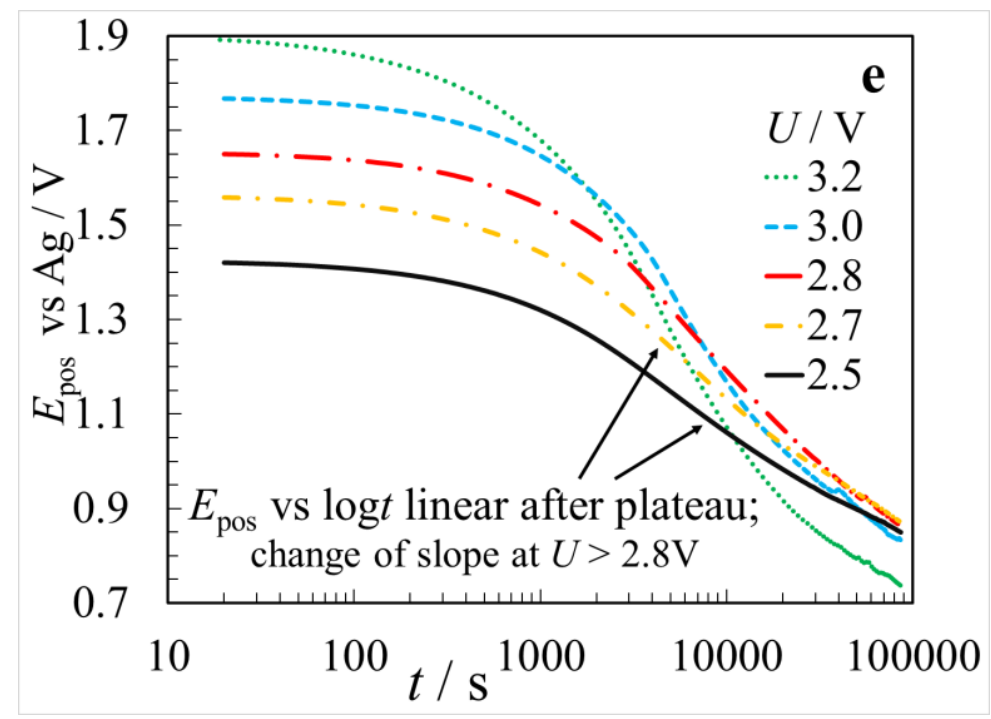

Figure 4. Open circuit potential of individual electrodes after $2 \mathrm{~h}$ hold of carbon/carbon cells in EMImTFSI at various $U$, expressed vs. $t^{1 / 2}$ for (a) negative (-) CXER-H electrode, (b) positive (+) CXER-H electrode, (d) positive (+) CXER-L electrode, and vs. $\log t$ for (c) negative (-) CXER-H electrode and (e) positive (+) CXER-L electrode.

When $\mathrm{BMImBF}_{4}$ (with $320 \mathrm{ppm}$ of $\mathrm{H}_{2} \mathrm{O}$ ) was used as electrolyte, the SD of electrodes followed the same trend as in EMImTFSI and depended on the nature of the carbon electrodes - diffusion-controlled SD for electrodes with the high surface area carbons YP-80F (Figures 5a and 5b) and CXER-H, and activation-controlled SD for low surface area CXER-L with developed mesoporosity (Figure 5c). Differently from EMImTFSI with practically equal ion sizes, the absolute change in electrodes' potential during SD was more pronounced for the negative electrode, especially at high applied cell potential, due to differences in the charge redistribution extent caused by the bulky $\mathrm{BMIm}^{+}$ions as opposed to the much smaller $\mathrm{BF}_{4}^{-}$being adsorbed on the positive electrode (Figures 5a and 5b) (see Figure S1 in Supplementary 
materials). The difference in SD extent with electrode polarity was somewhat less noticeable with the CXER-L carbon, where the $\mathrm{BMIm}^{+}$cations could move more freely inside the mesopores (Figure 5c and 5d). Compared to EMImTFSI, much higher hold potentials could be applied to the cells without changes occurring in the individual electrodes' SD characteristics. The SD profiles of all the studied types of electrodes changed at cell potential hold $U>3.2 \mathrm{~V}$, revealed specifically by the pronounced change in the slope of the potential vs. $t^{1 / 2}$ curve and potential vs. $\log t$ curve for the negative electrodes (Figures $5 \mathrm{~b}$ and $5 \mathrm{~d}$ ), with an accompanying quick decline in potential, and less evident change for the positive electrodes (Figures 5a and $5 \mathrm{c}$ ). At all values of cell potential hold in $\mathrm{BMImBF}_{4}$, the reactions of moisture present as impurity are considered partly responsible for the potential decay, in addition to charge redistribution. At $U>3.2 \mathrm{~V}$, electrolyte decomposition, i.e. reduction of the imidazolium cation, starts to take place on the negative electrode, where the rather high water content of $320 \mathrm{ppm}$ in the purchased $\mathrm{BMImBF}_{4}$ could have an accelerating effect. However, after heating the IL in vacuum to reduce the water content down to $22 \mathrm{ppm}$, the SD profiles of the negative electrode only slightly changed, yet the stability limit remained at $U<3.4 \mathrm{~V}$ (not shown in the figures). Also, $\mathrm{BMImBF}_{4}$ drying did not affect the SD profiles of the positive electrode, which is in accordance with an ageing study, where it was shown that higher water concentration in non-aqueous electrolytes had essentially a detrimental effect on the negative electrode [30]. It is expected that the metallic impurities inside the xerogel-carbon electrodes contribute to faradaic processes inducing also SD in $\mathrm{BMImBF}_{4}$ electrolyte, however with possibly less extreme effect on the cell stability. For further confirmation, floating tests were also performed and are discussed in Section 3.3 for this type of IL. 
The SD and leakage current experiments in 2-electrode cells with and without reference electrode lead to conclude uniformly that the stability limit of carbon/carbon cells in EMImTFSI ionic liquid stays below $2.8 \mathrm{~V}$, indicated by insufficient reproducibility of SD curves in 2-electrode configuration beyond this cell potential, significant change of individual electrode SD characteristics, as well as increased leakage current values. The stability potential limit of cells in $\mathrm{BMImBF}_{4}$ ionic liquid is remarkably higher, reaching $3.2 \mathrm{~V}$, and therefore it is expected that the processes behind degradation of the two IL systems are in essence of different type.
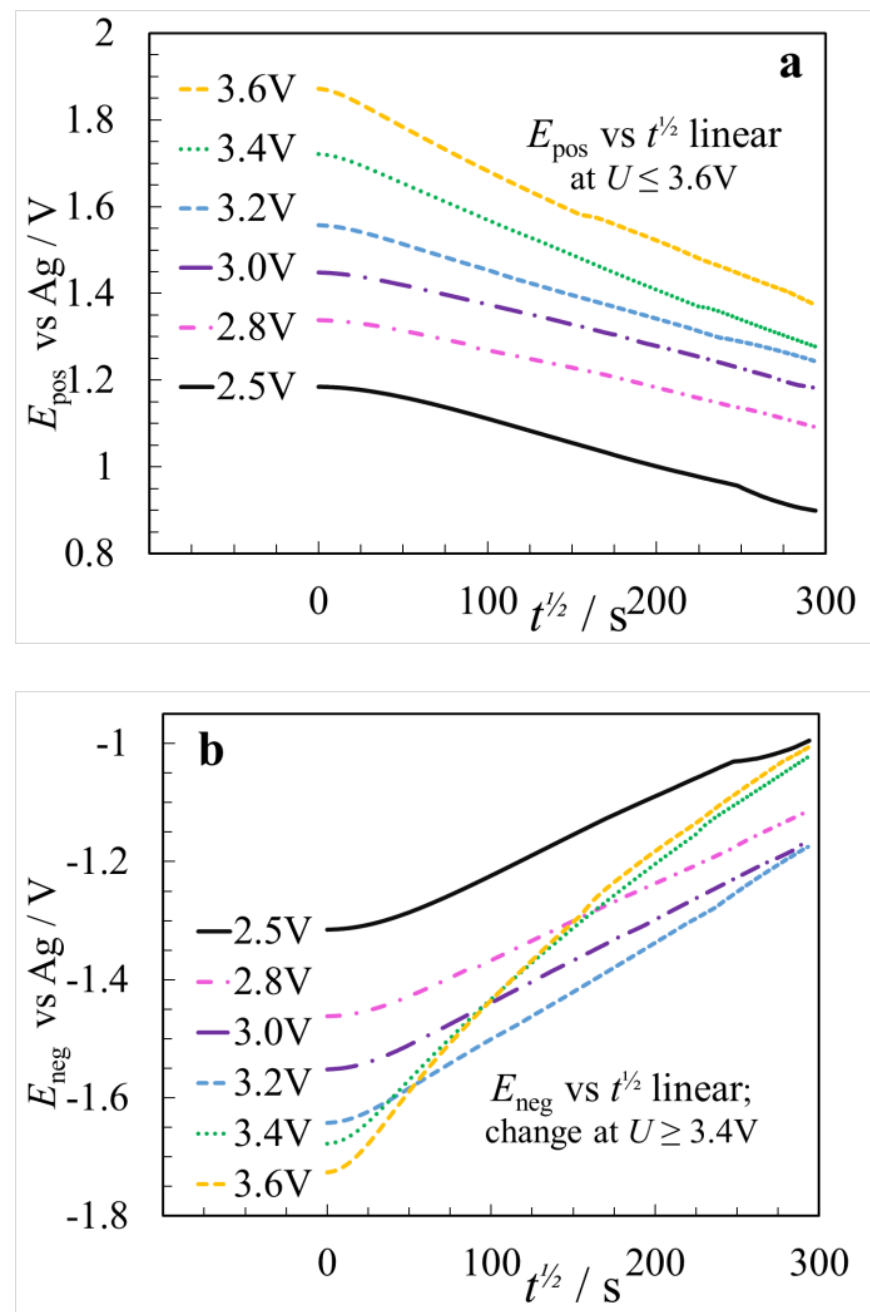

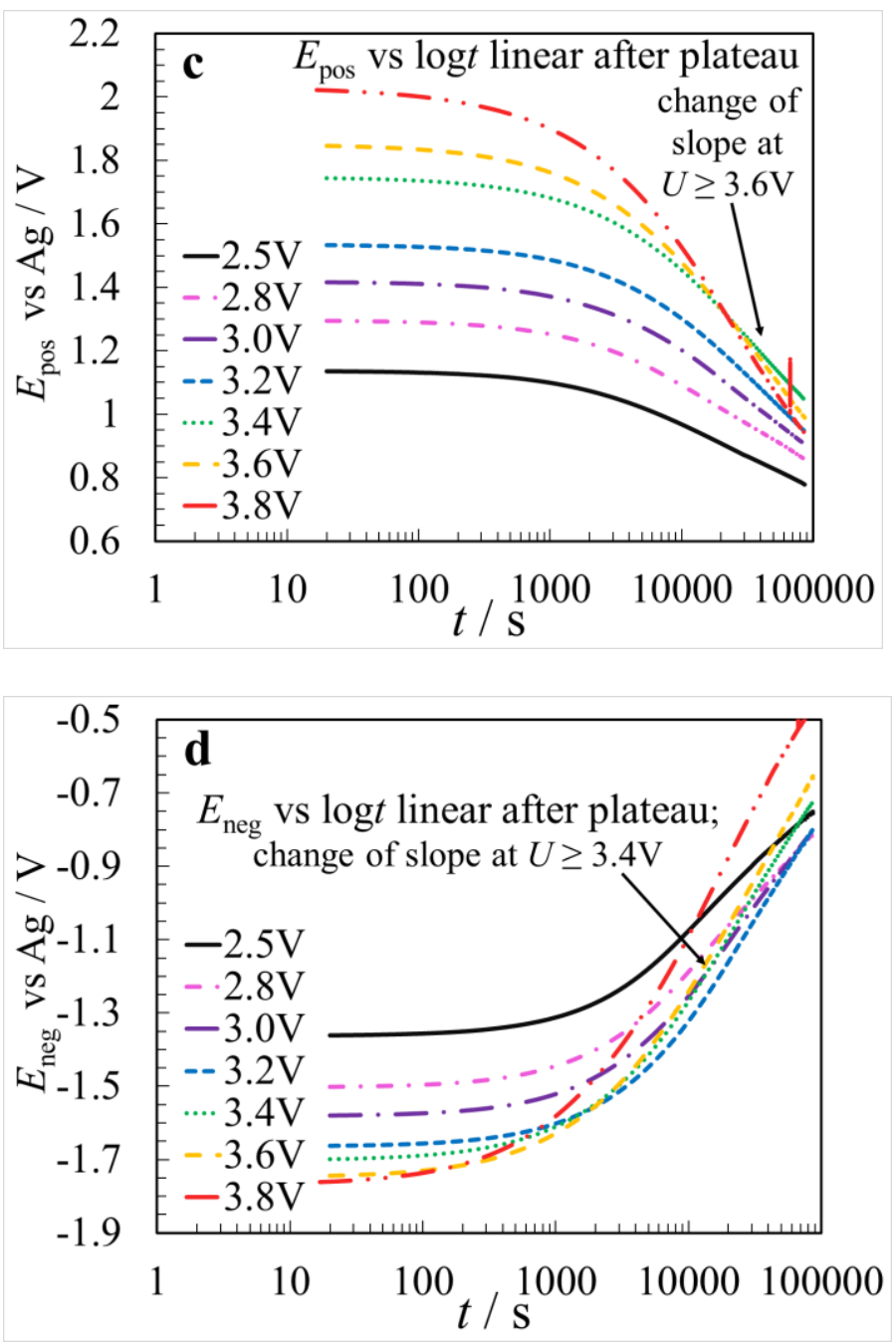

Figure 5. Open circuit potential of individual electrodes after $2 \mathrm{~h}$ hold of carbon/carbon cells in $\mathrm{BMImBF}_{4}$ (with $320 \mathrm{ppm}$ of $\mathrm{H}_{2} \mathrm{O}$ ) at various $U$, expressed vs. $t^{1 / 2}$ for (a) positive (+) YP-80F and (b) negative (-) YP-80F electrode, and vs. logt for (c) positive (+) CXER-L and (d) negative (-) CXER-L electrode.

3.3. Correlation between the cell potential limits from SD analysis and floating potential tests

Constant potential hold (floating) was applied to the cells in order to establish the stability limits, based on the currently accepted end-of-life criteria for EDLCs, e.g., either less than $20 \%$ decrease in capacitance or $100 \%$ increase in resistance $[16,17]$. 
CXER-H / CXER-H cells in EMImTFSI demonstrated rather good stability when floating was realized at $U=2.8 \mathrm{~V}$ during 150 hours, with resistance increase being only $3 \%$ while the discharge capacitance increased by $4 \%$. However, at $U=3.0 \mathrm{~V}$, the cell failure by resistance $(+109 \%)$ was established already after $130 \mathrm{~h}$, with capacitance increasing also by $4 \%$, and at $U=3.2 \mathrm{~V}$, only $60 \mathrm{~h}$ floating resulted in failure by the resistance criterion. According to Figures $6 \mathrm{a}$ and $6 \mathrm{~b}$, the leakage current steady-state values increase gradually throughout the repeated $2 \mathrm{~h}$ floating periods at $U$ $=2.8 \mathrm{~V}$ or $3.0 \mathrm{~V}$ during the floating tests.

In order to better understand the causes of performance fade, the cells were opened after floating for SEM-EDX analysis of electrodes and current collectors. Pitting corrosion was detected by SEM on the positive current collectors after floating of the CXER-H/CXER-H cell in EMImTFSI at $U=2.8 \mathrm{~V}$ and higher potential (Figure 7), which justifies the increase of leakage current values throughout the floating test. This observation explains also the increase of discharge capacitance values throughout the float test (in opposition to the generally observed capacitance decrease), due to the capacity related with the anodic dissolution (corrosion) of the positive current collector. The shuttle effects of increasing amount of diffusing oxidized metallic species originating from the corrosion of the positive current collector are expected to cause reduction reactions on the negatively charged electrode in EMImTFSI, in addition to electrode surface reactions with the metallic impurities already present in the CXER-H and CXER-L carbons. The shuttling of corrosion products was proven by SEM-EDX analysis of electrodes after floating CXER-H-based cells in EMImTFSI at $U \geq 2.8 \mathrm{~V}$, showing a range of $0.48-0.95$ at\% of $\mathrm{Cr}$ and $0.45-1.18$ at\% of $\mathrm{Fe}$ at various locations on both electrode polarities, as compared to 0.06 at\% of $\mathrm{Cr}$ and 0.2 at\% of Fe in fresh CXER-H electrodes. Hence, metallic impurities play an important 
role in the EMImTFSI cells' SD processes, especially at floating cell potential higher than $2.8 \mathrm{~V}$, where metallic dissolved species are produced due to positive current collector corrosion, and diffuse easily inside the wide mesopores of CXER-L electrodes.

Similar conclusions were made from the floating tests with YP-80F electrodes, but the failure times were slightly longer $-220 \mathrm{~h}$ at $U=3.0 \mathrm{~V}$ and $100 \mathrm{~h}$ at $U=3.2 \mathrm{~V}-$ owing to the higher purity and more passivated surface of this commercial carbon intended for EDLC application. Hence, SD and leakage current tests, as well as longlasting floating potential tests, all demonstrate that the maximum operating cell potential in EMImTFSI should be lower than $2.8 \mathrm{~V}$ to avoid fast degradation of the cells.
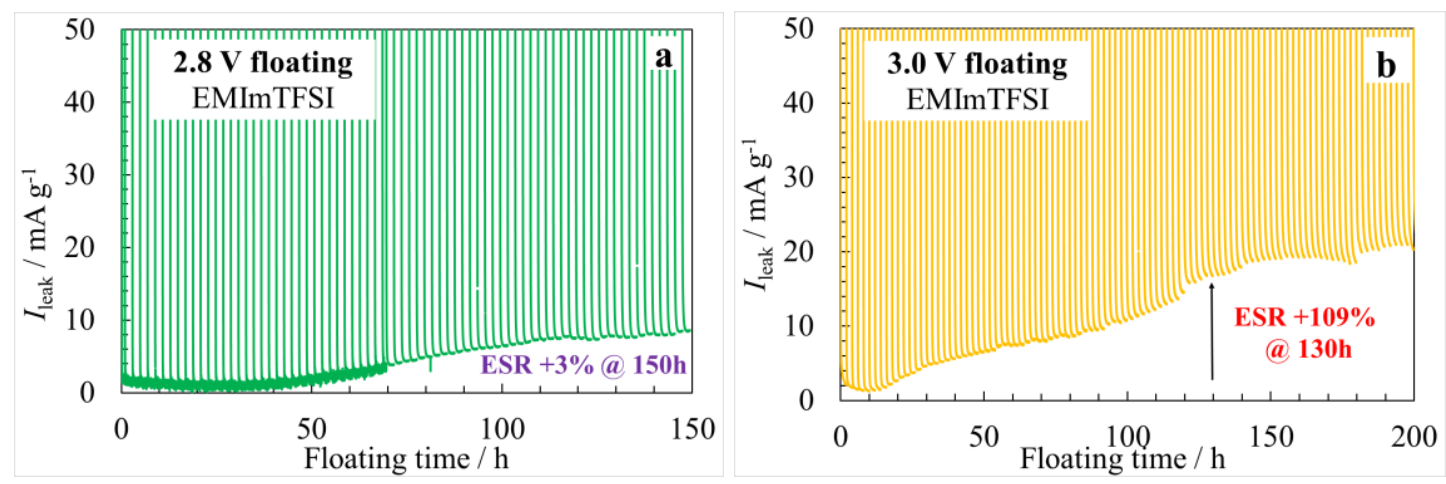

Figure 6. Leakage current profiles of CXER-H/CXER-H cells in EMImTFSI during repeated $2 \mathrm{~h}$ hold periods at (a) $U=2.8 \mathrm{~V}$ and (b) $U=3.0 \mathrm{~V}$. 


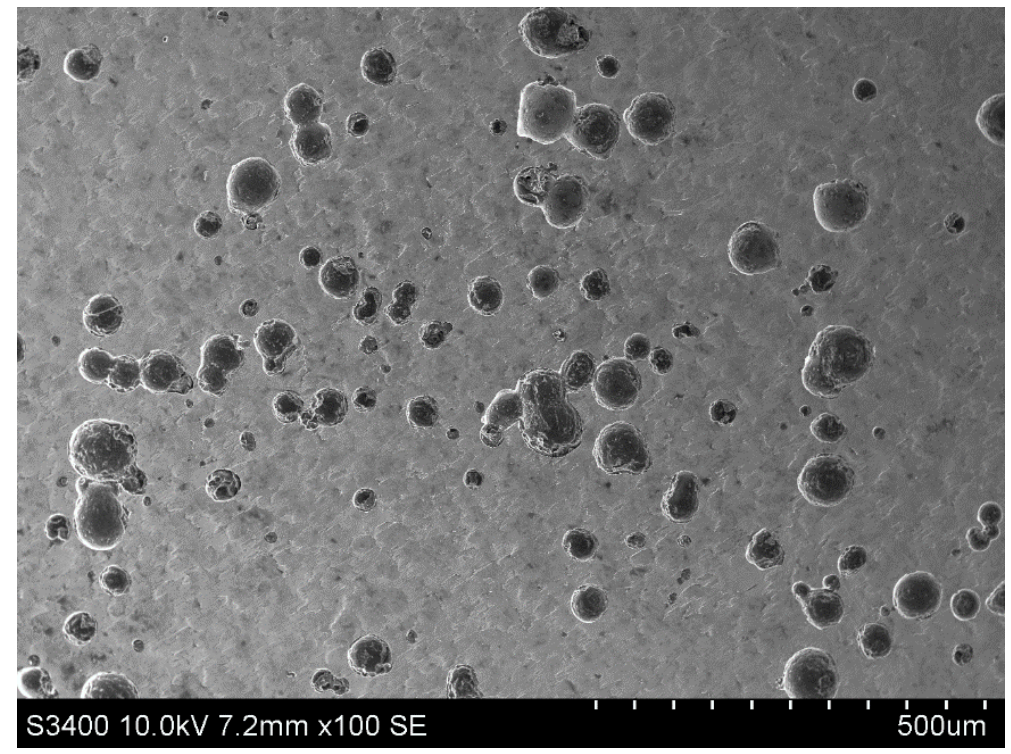

Figure 7. SEM image showing pitting of the positive current collector (coin cell spacer against carbon electrode) after floating of the CXER-H/CXER-H cell in EMImTFSI during 150 hours at $2.8 \mathrm{~V}$.

When using the $\mathrm{BMImBF}_{4}$ electrolyte containing $320 \mathrm{ppm}$ of water, the previously shown SD and leakage current experiments at various cell potentials suggested a stability limit at close proximity of $3.4 \mathrm{~V}$, practically regardless of the carbon material used (Figure 5). Such limit was confirmed by floating at $U=3.2 \mathrm{~V}$ on a YP-80F/YP-80F cell, where stable leakage current is demonstrated throughout the $400 \mathrm{~h}$ duration of the test, while the cell resistance increased by $60 \%$ and capacitance decreased by $13 \%$ (Figure $8 \mathrm{a}$ ). At $U=3.4 \mathrm{~V}$, failure by both criteria (110\% resistance increase and $21 \%$ capacitance decrease) took place after $250 \mathrm{~h}$ of floating (Figure $8 \mathrm{~b}$ ); and when floating was realized at $U=3.6 \mathrm{~V}$, failure occurred after 80 hours. As already established by the SD analysis, reducing the water content down to $22 \mathrm{ppm}$ did not remarkably influence the ageing characteristics: after $250 \mathrm{~h}$ of floating at $U=$ $3.4 \mathrm{~V}$, the capacitance decreased by $21 \%$ and the resistance increased by $74 \%$, whilst at $U=3.6 \mathrm{~V}$ the system failure occurred after $80 \mathrm{~h}$. However, after floating at $3.4 \mathrm{~V}$ in $\mathrm{BMImBF}_{4}$, regardless of the water content, SEM-EDX analysis did not show any 
corrosion of the positive current collector, contrary to our previous observations in EMImTFSI. Consequently, the higher values of leakage current throughout the floating test at $3.4 \mathrm{~V}$ in $\mathrm{BMImBF}_{4}$ as compared to $3.2 \mathrm{~V}$ (Figure 8), are likely related to slow electrochemical degradation reactions of the electrolyte (including contributions from trace water impurity) on carbon electrodes, leading to somewhat slower decay of EDLC performance as compared to corrosion-induced and related impurity reactions in EMImTFSI. In $\mathrm{BMImBF}_{4}$, the difference of stability between the YP-80F and CXER-H-based cells was much less noticeable than in EMImTFSI, suggesting that the reactions involving the $\mathrm{TFSI}^{-}$anion (likely catalytic reactions) are very sensitive to the presence of metallic impurities in the electrodes (or electrolyte). After the floating tests in $\mathrm{BMImBF}_{4}$, the levels of $\mathrm{Cr}$ and $\mathrm{Fe}$ determined on various locations of the positive and negative electrodes were below 0.1 at $\%$.
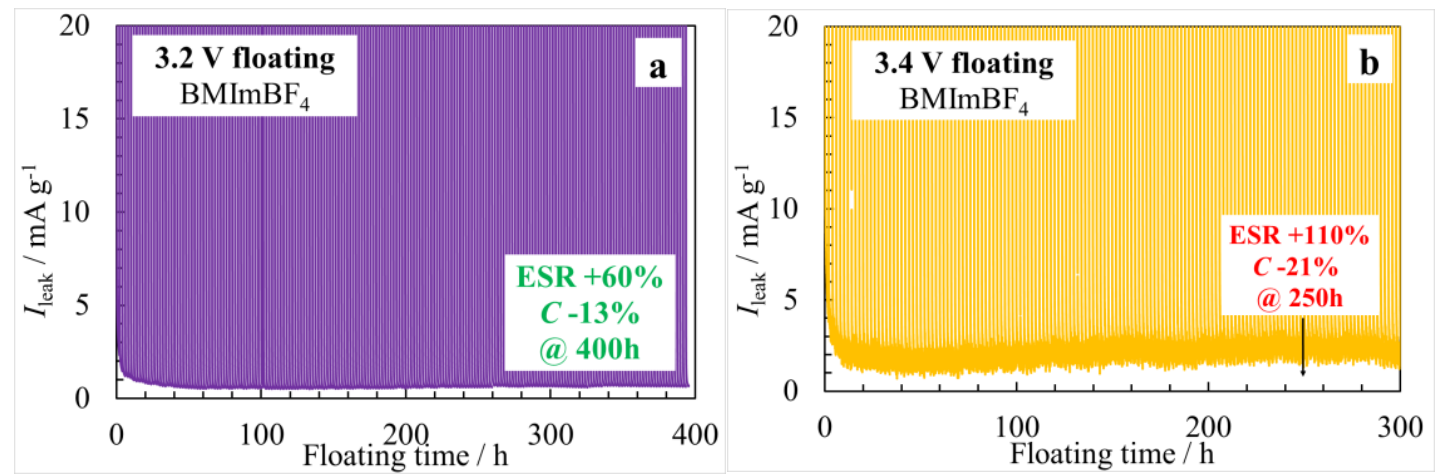

Figure 8. Leakage current profiles of $\mathrm{YP}-80 \mathrm{~F} / \mathrm{YP}-80 \mathrm{~F}$ cells in $\mathrm{BMImBF}_{4}$ with 320 ppm of water during repeated $2 \mathrm{~h}$ hold periods at (a) $U=3.2 \mathrm{~V}$ and (b) $U=3.4 \mathrm{~V}$.

Since the stainless steel current collectors are not corroded during floating of cells in $\mathrm{BMImBF}_{4}$, this electrolyte is also expected to be less reactive than EMImTFSI with the iron impurities present in the xerogel electrodes. Therefore, the detected problems with SD data reproducibility in EMImTFSI at $U>2.8 \mathrm{~V}$ and changes in SD curve 
shape can be directly related to the corrosion of current collectors by the TFSI ions and other overcharge induced reduction and oxidation decomposition reactions of the IL involving metallic impurities. Clearly, $\mathrm{TFSI}^{-}$based electrolytes are more active towards corrosive attack of positive current collector than $\mathrm{BF}_{4}^{-}$based. Therefore, it could also be expected that faradaic reactions with $\mathrm{TFSI}^{-}$on the xerogel carbon electrode surface, where higher quantity of metallic impurities have been detected by ICP-OES, are more pronounced than in $\mathrm{BF}_{4}^{-}$electrolyte, especially with the wellaccessible surface of the CXER-L carbon. Therefore, the slower SD rate in $\mathrm{BMImBF}_{4}$ as opposed to EMImTFSI with CXER-L electrodes is well explained by the high reactivity towards iron and the occurrence of shuttle effects between electrodes. Otherwise, in the hypothesis that SD is governed by charge redistribution for both ILs, the SD extent would be higher with the bulky BMIm ${ }^{+}$cation than EMIm ${ }^{+}$.

\section{Conclusions}

Since most applications of EDLCs require good retention of the charged state over several hours/days, it is very important to estimate/monitor their self-discharge (SD) and predict their life time in applied conditions. Although ionic liquids (ILs) have been claimed a promising class of electrolytes for extending the cell potential, there are only very few studies on confirming such statement during long-term usage, and to the best of our knowledge the reasons for potential decay at open circuit have not been identified before this work.

We have found that the properties of the carbon materials implemented for electrodes manufacturing strongly influence the SD extent in imidazolium-based ILs, and that quicker SD occurs when implementing mesoporous carbons. The faradaic processes related with the reactions of impurities (like water traces in electrolyte or metallic impurities in carbon) and/or IL-induced oxidation/reduction seem to have 
more pronounced effect on the observed cell/electrode potential changes at open circuit than the inevitable process of charge redistribution. Also, the IL chemical composition, in this case the type of anion, has a profound influence on the device electrochemical stability, due to the occurrence of stainless steel positive current collector corrosion in case of EMImTFSI.

Based on studies on individual electrodes, we have shown that, at lower cell potential hold, diffusion-controlled SD takes place with carbons having a high micropore volume, whereas activation-controlled SD occurs with mesoporous carbons, where impurities and IL ions have quicker access to the pores' surface. A change in SD mechanism was detected on both electrodes at cell potential hold higher than $2.8 \mathrm{~V}$ in EMImTFSI, confirmed by start of quick degradation at same conditions in floating tests. Additionally, the time to reach failure during floating at high cell potential strongly depends on the amount of metallic impurities in the carbon electrodes with the TFSI $^{-}$based electrolyte, showing the high activity of this electrolyte towards reactions with several metals. With $\mathrm{BMImBF}_{4}$, the change of SD process occurs at $\sim 3.4 \mathrm{~V}$ and also here the floating tests confirm an accelerated degradation at this potential, as compared to lower cell potential hold of $3.2 \mathrm{~V}$. The stability of the cell is essentially limited by the negative electrode, yet metallic impurities do not play a significant role (also the current collectors are not corroded).

In sum, the monitoring of changes in self-discharge mechanism (on either electrode polarity) and of increase in leakage current level is a quick and sensitive "tool" for evaluating the stability potential limits of EDLCs in ionic liquid, as compared to long-term tests by floating (i.e. life time) or galvanostatic cycling. Therefore, self-discharge analysis provides a lot of more valuable information than merely the evaluation of supercapacitor's ability to retain a charged state. This kind of 
approach for stability limit evaluation is suggested as further topic for studies in other electrolytic media (not limited to IL electrolytes) and types of activated carbons for EDLCs. The long-term stability relation to self-discharge characteristics could be further extended also to different hybrid and redox type electrochemical capacitors.

\section{Acknowledgements}

Narodowe Centrum Nauki (NCN) is acknowledged for supporting the OPUS project UMO 2014/15/B/ST4/04957. The authors would like to thank Kuraray Chemical Co. (Japan) for the YP-80F sample, and T. Romann from the University of Tartu (Estonia) for the Gaussian 03 calculations.

\section{References}

[1] F. Béguin, E. Frackowiak, Supercapacitors. Materials, Systems, and Applications, Wiley-VCH, Weinheim, 2013.

[2] J. Niu, B.E. Conway, E.G. Pell, Comparative studies of self-discharge by potential decay and floatcurrent measurements at $\mathrm{C}$ double-layer capacitor and battery electrodes, J. Power Sources 135 (2004) 332-343.

[3] A. Lewandowski, P. Jakobczyk, M. Galinski, M. Biegun, Self-discharge of electrochemical double layer capacitors, Phys. Chem. Chem. Phys. 15 (2013) 8692-8699.

[4] J. Black, H.A. Andreas, Effects of charge redistribution on self-discharge of electrochemical capacitors, Electrochim. Acta 54 (2009) 3568-3574.

[5] J. Black, H.A. Andreas, Prediction of the self-discharge profile of an electrochemical capacitor electrode in the presence of both activationcontrolled discharge and charge redistribution, J. Power Sources 195 (2010) 929-935. 
[6] J. Kowal, E. Avaroglu, F. Chamekh, A. Senfelds, T. Thien, D. Wijaya, D.U. Sauer, Detailed analysis of the self-discharge of supercapacitors, J. Power Sources 196 (2011) 573-579.

[7] B.E. Conway, W.G. Pell, T.C. Liu, Diagnostic analyses for mechanisms of self-discharge of electrochemical capacitors and batteries, J. Power Sources 65 (1997) 53-59.

[8] H.A. Andreas, Self-Discharge in Electrochemical Capacitors: A Perspective Article, J. Electrochem. Soc. 162(5) (2015) A5047-A5053.

[9] J.M. Black, H.A. Andreas, Pore Shape Affects Spontaneous Charge Redistribution in Small Pores, J. Phys. Chem. C 114 (2010) 12030-12038.

[10] J.W. Graydon, M. Panjehshahi, D.W. Kirk, Charge redistribution and ionic mobility in the micropores of supercapacitors, J. Power Sources 245 (2014) $822-829$.

[11] F. Soavi, C. Arbizzani, M. Mastragostino, Leakage currents and self-discharge of ionic liquid-based supercapacitors, J. Appl. Electrochem. 44 (2014) 491496.

[12] N. Handa, T. Sugimoto, M. Yamagata, M. Kikuta, M. Kono, M. Ishikawa, A neat ionic liquid electrolyte based on FSI anion for electric double layer capacitor, J. Power Sources 185 (2008) 1585-1588.

[13] D. Weingarth, H. Noh, A. Foelske-Schmitz, A. Wokaun, R. Kötz, A reliable determination method of stability limits for electrochemical double layer capacitors, Electrochim. Acta 103 (2013) 119-124.

[14] K. Xu, S.P. Ding, T.R. Jow, Toward Reliable Values of Electrochemical Stability Limits for Electrolytes, J. Electrochem. Soc. 146 (1999) 4172-4178.

[15] K. Xu, M.S. Ding, T.R. Jow, A better quantification of electrochemical stability limits for electrolytes in double layer capacitors, Electrochim. Acta 46 (2001) 1823-1827.

[16] Technical information document „SkelCap User Manual“ under Downloads on www.skeletontech.com by Skeleton Technologies.

[17] D. Weingarth, A. Foelske-Schmitz, R. Kötz, Cycle versus voltage hold Which is the better stability test for electrochemical double layer capacitors?, J. Power Sources 225 (2013) 84-88. 
[18] N. Rey-Raap, J. Angel Menéndez, A. Arenillas, RF xerogels with tailored porosity over the entire nanoscale, Micropor. Mesopor. Mater. 195 (2014) 266-275.

[19] M. Canal-Rodríguez, A. Arenillas, N. Rey-Raap, G. Ramos-Fernández, I. Martín-Gullón, J. Angel Menéndez, Graphene-doped carbon xerogel combining high electrical conductivity and surface area for optimized aqueous supercapacitors, Carbon 118 (2017) 291-298.

[20] C. Largeot, C. Portet, J, Chmiola, P.-L. Taberna, Y. Gogotsi, P. Simon, Relation between the ion Size and Pore Size for an Electric Double-Layer Capacitor, J. Am. Chem. Soc. 130 (2008) 2730-2731.

[21] M. Lazzari, F. Soavi, M. Mastragostino, Mesoporous Carbon Design for Ionic Liquid-Based, Double-Layer Supercapacitors, Fuel Cells 10 (2010) 840-847.

[22] M. Lazzari, M. Mastragostino, A.G. Pandolfo, V. Ruiz, F. Soavi, Role of Carbon Porosity and Ion Size in the Development of Ionic Liquid Based Supercapacitors, J. Electrochem. Soc. 158 (2011) A22-A25.

[23] A.V. Neimark, Y. Lin, P.I. Ravikovitch, M. Thommes, Quenched solid density functional theory and pore size analysis of micro-mesoporous carbons, Carbon 47 (2009) 1617-1628.

[24] G.Y. Gor, M. Thommes, K.A. Cychosz, A.V. Neimark, Quenched solid density functional theory method for characterization of mesoporous carbons by nitrogen adsorption, Carbon 50 (2012) 1583-1590.

[25] L.R. Radovic, B. Bockrath, On the chemical nature of graphene edges: origin of stability and potential for magnetism in carbon materials, J. Am. Chem. Soc., 127 (2005) 5917-5927.

[26] A. Laheäär, P. Przygocki, Q. Abbas, F. Béguin, Appropriate methods for evaluating the efficiency and capacitive behavior of different types of supercapacitors, Electrochem. Commun. 60 (2015) 21-25.

[27] H.A. Andreas, K. Lussier, A.M. Oickle, Effect of Fe-contamination on rate of self-discharge in carbon-based aqueous electrochemical capacitors, J. Power Sources 187 (2009) 275-283.

[28] E. Markevich, R. Sharabi, V. Borgel, H. Gottlieb, G. Salitra, D. Aurbach, G. Semrau, M.A. Schmidt, Electrochim. Acta 55 (2010) 2687-2696.

[29] P.C. Howlett, E.I. Izgorodina, M. Forsyth, D.R. MacFarlane, Z. Phys. Chem. 220 (2006) 1483-1498. 
[30] D. Cericola, P.W. Ruch, A. Foelske-Schmitz, D. Weingarth, R. Kötz, Effect of Water on the Aging of Activated Carbon Based Electrochemical Double Layer Capacitors During Constant Voltage Load Tests, Int. J. Electrochem. Sci. 6 (2011) 988-996. 